\title{
Prevalence and predictors of sleep disturbance among liver diseases in long-term transplant survivors
}

\author{
Mamatha Bhat MD MSc ${ }^{1 *}$, Jonathan M Wyse MD MSc${ }^{2 *}$, Erica Moodie $\mathrm{PhD}^{3}$, Peter Ghali MD MSc ${ }^{1}$, \\ Nir Hilzenrat MD², Philip Wong MD MSc ${ }^{1}$, Marc Deschênes MD ${ }^{1}$
}

\begin{abstract}
M Bhat, JM Wyse, E Moodie, et al. Prevalence and predictors of sleep disturbance among liver diseases in long-term transplant survivors. Can J Gastroenterol Hepatol 2015;29(8):440-444.
\end{abstract}

BACKGROUND: Patients with cirrhosis are known to experience sleep disturbance, which negatively impacts health-related quality of life. OBJECTIVE: To assess the prevalence and predictors of sleep disturbance before and after liver transplantation (LT).

METHODS: Both pre- and post-LT patients were administered the Basic Nordic Sleep Questionnaire. The primary outcome was overall sleep satisfaction; the secondary outcomes were sleep latency and sleep duration.

RESULTS: Eighty-three patients participated pre-LT and 273 post-LT. Overall, participants having completed both pre- and post-LT questionnaires reported satisfactory sleep $61 \%$ of the time before LT and $65 \%$ of the time after LT. However, on review of all questionnaires, patients with alcoholic liver disease $(\mathrm{ETOH})$ experienced dramatically less sleep disturbance (OR 0.13 [95\% CI 0.03 to 0.60]) post-LT, whereas those with hepatitis $\mathrm{C}$ remained without improvement (OR 0.90 [95\% CI [0.38 to 2.15]). On logistic regression, patients with ETOH had statistically less sleep satisfaction pre-LT (OR 5.8 [95\% CI 1.0 to 40.5$]$ ) and significantly better sleep satisfaction post-LT (OR 0.50 [95\% CI 0.20 to 1.00$]$ ]) compared with those with hepatitis C. In addition, both ETOH and other conditions had significantly better sleep latency than hepatitis $\mathrm{C}$ patients.

CONCLUSIONS: Sleep parameters for patients who undergo LT for hepatitis $\mathrm{C}$ do not improve following $\mathrm{LT}$ as much as they do in patients transplanted for ETOH. Following LT, patients transplanted for ETOH are significantly more satisfied with their sleep than those transplanted for hepatitis C. Physicians should address and manage sleep quality after LT, so as to ultimately improve quality of life.

Key Words: Sleep; Liver transplant; Hepatitis C; BNSQ (Basic Nordic Sleep Questionnaire)

A long-term survival after liver transplantation (LT) continues to improve, there has been greater focus on issues related to healthrelated quality of life (HRQoL) (1-4). Sleep disturbance in patients with cirrhosis has a clear negative impact on HRQoL $(5,6)$ and even survival (7). However, it is uncertain how sleep parameters are affected following LT.

Prevalence of sleep disturbance in cirrhotic patients without hepatic encephalopathy has been reported to be as high as $47.7 \%$ (8). The mechanisms of sleep disturbance in cirrhotic patients are not well elucidated, but appear temporally related to the liver disease itself (8). The absence of circadian oscillation in plasma melatonin results in a lack of synchronicity between internal and social rhythms (9). A case report involving a patient with hepatitis $\mathrm{C}$ cirrhosis attested to this lack of melatonin oscillation pretransplant, with full restoration of circadian rhythm following LT (10). One would assume that restoration of circadian rhythms would enhance sleep quality after LT. Three
La prévalence et les prédicteurs des troubles du sommeil chez les survivants d'une transplantation hépatique de longue date

HISTORIQUE : Les patients atteints de cirrhose se caractérisent par des troubles du sommeil qui nuisent à leur qualité de vie liée à la santé. OBJECTIF : Évaluer la prévalence et les prédicteurs de troubles du sommeil avant et après une transplantation hépatique (TH).

MÉTHODOLOGIE : Des patients ont participé au questionnaire de base sur le sommeil dans les pays nordiques avant ou après une TH. La satisfaction générale vis-à-vis du sommeil était le résultat principal, tandis que le délai d'endormissement et la durée du sommeil étaient les résultats secondaires.

RÉSULTATS : Quatre-vingt-trois patients ont participé au questionnaire avant la TH et 273, après la TH. Dans l'ensemble, les participants qui avaient rempli les deux questionnaires ont déclaré avoir un sommeil satisfaisant $61 \%$ du temps avant la TH et $65 \%$ du temps après la TH. Cependant, à l'analyse de tous les questionnaires, les patients atteints d'une stéatose hépatique non alcoolique $(\mathrm{ETOH})$ éprouvaient beaucoup moins de troubles du sommeil ( $\mathrm{RC} 0,13$ [95 \% IC 0,03 à 0,60]) après la $\mathrm{TH}$, tandis que le sommeil de ceux qui étaient atteints d'hépatite $\mathrm{C}$ ne s'améliorait pas (RC 0,90 [95\% IC [0,38 à 2,15]). À la régression logistique, les patients atteints d'ETOH étaient statistiquement moins satisfaits vis-à-vis de leur sommeil avant la TH (RC 5,8 [95 \% IC 1,0 à $40,5]$ ) et beaucoup plus satisfaits vis-à-vis de leur sommeil après la $\mathrm{TH}$ (RC 0,50 [95 \% IC 0,20 à 1,00]) que ceux qui étaient atteints d'hépatite C. De plus, tant l'ETOH que les autres problèmes de santé s'associaient à une réduction considérable du délai d'endormissement par rapport aux patients atteints d'hépatite C.

CONCLUSIONS : Les paramètres du sommeil chez les patients qui subissent une $\mathrm{TH}$ en raison de l'hépatite $\mathrm{C}$ ne s'améliorent pas autant après la $\mathrm{TH}$ que chez les patients greffés en raison de l'ETOH. Après la $\mathrm{TH}$, les patients greffés en raison de l'ETOH sont considérablement plus satisfaits de leur sommeil que ceux greffés en raison de l'hépatite C. Les médecins devraient évaluer et prendre en charge la qualité du sommeil après la TH afin de finir par améliorer la qualité de vie.

studies measuring HRQoL in the post-LT period, although not directly focusing on sleep disturbance itself, found inconsistent results. One reported sleep as the most common problem in post-LT patients $(45 \%)$ (11), a second found sleep quality improved back to the level of the general population (12) and a third (13) suggested less sleep disturbance, although impairments that remained in excess of $20 \%$ relative to the individual's premorbid status.

We performed a retrospective observational study to determine the prevalence and risk factors for sleep disturbance before and after LT in long-term survivors ( $>6$ months). We hypothesized that patients with hepatitis $\mathrm{C}$ virus (HCV) infection, which is universally recurrent following LT, would sleep less well than those whose liver disease did not recur. The primary outcome of our study was overall self-reported sleep satisfaction; the secondary outcomes were sleep latency (time required to fall asleep) and total sleep duration.

*Authors who contributed equally

${ }^{1}$ Division of Gastroenterology, McGill University Health Centre; ${ }^{2}$ Division of Gastroenterology, Sir Mortimer B Davis-Jewish General Hospital; 3 Department of Epidemiology, Biostatistics, $\mathcal{E}$ Occupational Health, McGill University, Montreal, Quebec

Correspondence: Dr Mamatha Bhat, Division of Gastroenterology, Royal Victoria Hospital, 687 Pine Avenue West, Montreal,

Quebec H3A 1A1. Telephone 514-801-6220, fax 514-843-1421, e-mail mamatha.bhat@mail.mcgill.ca

Received for publication December 15, 2014. Accepted April 18, 2015 


\section{METHODS}

All patients seen at the outpatient LT clinic of the McGill University Health Centre (Montreal, Quebec), between July 1998 and December 2012 were invited to participate in the present study. Patients were administered the Basic Nordic Sleep Questionnaire (BNSQ) (14) at each outpatient visit pre-LT and every follow-up visit post-LT (Appendix 1 [go to www.pulsus.com]). Not all patients completed questionnaires at each visit because they had the right to refuse at any time. For pre-LT questionnaires, the survey completed closest to transplant was chosen. If a patient was already transplanted when first approached for the study, only post-LT questionnaires existed. The questionnaire furthest away from LT was chosen as being the most representative of the patient's post-LT sleep health.

The BNSQ is a quantitative measure of subjective sleep complaints, and has been validated in several studies (14-20). Three items from this questionnaire have been shown to most closely correlate with objective sleep polysomnography $(21,22)$ and were, therefore, included in the analysis:

- Overall sleep satisfaction (binary: yes, no)

- Sleep latency (binary: time to fall asleep $\geq 30 \mathrm{~min}$; yes, no)

- Sleep duration (binary: total sleep duration $\geq 6 \mathrm{~h}$; yes, no)

Patients were classified into three categories based on their liver disease: $\mathrm{HCV}$, alcoholic $(\mathrm{ETOH})$ and other. Demographic and clinical characteristics, such as age, sex, body mass index (BMI) and Model for End-stage Liver Disease (MELD) scores, were obtained. MELD scores were calculated based on laboratory data immediately pre-LT. The number of postoperative days spent in hospital was also included as a surrogate for perioperative complications at LT. At the time of each questionnaire, information regarding all medication use, including sleep aids, was recorded. Sleep aids included all benzodiazepines, such as lorazepam and diazepam, as well as quetiapine. The generic as well as pharmaceutical names were used to interrogate the transplant database as to the use of these sleep aids.

The present study was approved by the Institutional Review Board at the McGill University Health Centre, Montreal, Quebec.

\section{Statistical analysis}

Demographic and clinical characteristics such as sex, age, and bilirubin levels were summarized using descriptive statistics (medians and ranges for continuous covariates, proportions for binary covariates). Subject information was summarized by selecting the visit closest to the time of LT in the pre- and postoperative period, so that at most one visit per patient was included in each of the pre-LT and post-LT summary of characteristics.

The analyses were performed using a linear or a logistic regression model (multivariable analysis). To make use of all the information, the missing data were imputed using the MICE package in $\mathrm{R}$ and the analyses are based on 25 imputations. Because the analysis was exploratory in nature, all tests of association were performed at the 0.05 level of significance.

\section{Patient characteristics}

\section{RESULTS}

A total of 83 patients participated before LT $(32 \mathrm{HCV}$, nine ETOH, 42 other). The 'other' category included patients with cirrhosis secondary to hepatitis $B(n=4)$, nonalcoholic steatohepatitis or cryptogenic cirrhosis $(n=18)$, primary biliary cirrhosis $(n=5)$, primary sclerosing cholangitis $(n=9)$, autoimmune hepatitis $(n=2)$, polycystic liver disease $(n=2)$ and acute liver failure due to thrombosed hepatic artery $(n=2)$. Their demographic characteristics are listed in Table 1. There was a significantly greater percentage of men among patients with ETOH (89.9\%) than among patients with $\mathrm{HCV}$ (75\%) or other liver diseases (52\%). HCV patients used more sleep aids than those with ETOH or other chronic liver diseases ( $12.5 \%$ versus $0 \%$ and $4.8 \%$, respectively). No patients completed a questionnaire before repeat transplant.

A total of 273 patients participated following LT $(73 \mathrm{HCV}, 53 \mathrm{ETOH}$, 147 other). The 'other' category included patients with cirrhosis secondary
TABLE 1 Demographic characteristics of pre- and post-transplant patients

\begin{tabular}{lccc}
\hline & \multicolumn{3}{c}{ Liver transplant indication } \\
\cline { 2 - 4 } Characteristic & Hepatitis C & Alcoholic & Other \\
\hline Pretransplant & & & \\
$\mathrm{n}$ & 32 & 9 & 42 \\
Age, years & $55.25(28.9-66.7)$ & $58.20(40.9-64.0)$ & $58.55(23.3-71.6)$ \\
Male sex, \% & 75 & 89.9 & 52.4 \\
Using sleep aid, \% & 12.5 & 0 & 4.76 \\
Days before & $122(1-2659)$ & $71(14-947)$ & $138(3-2660)$ \\
$\quad$ transplant & \multicolumn{3}{|c}{} \\
Post-transplant & & 53 & \\
$\mathrm{n}$ & 73 & & 147 \\
Age, years & $55.1(37.7-74.0)$ & $57.2(42.3-70.8)$ & $57.8(18.0-73.1)$ \\
Male sex, \% & 76.7 & 86.8 & 67.3 \\
Second transplant, \% & 9.5 & 1.8 & 12.9 \\
Using sleep aid, \% & 15 & 16.9 & 13.6 \\
MELD score & $20(10-34)$ & $20(8-38)$ & $20(6-62)$ \\
Days in hospital stay & $20(6-81)$ & $20(8-141)$ & $21(7-376)$ \\
$\quad$ post-transplant & & & \\
Total days in hospital & $26(6-140)$ & $30(9-234)$ & $30(7-376)$ \\
$\quad$ stay & & & \\
Days since transplant & $868(31-5892)$ & $1510(56-6263)$ & $1427(19-6738)$ \\
\hline
\end{tabular}

Data presented as median (range) unless otherwise indicated. Sleep outcomes (\%) according to patient type, before and after surgery: information from the visit nearest to time of transplant before surgery and nearest to (but no less than) six months after surgery (at most one measure per person in each of the pre- and postoperative periods). MELD Model for End-stage Liver Disease

to hepatitis B $(n=35)$, nonalcoholic steatohepatitis or cryptogenic cirrhosis $(n=48)$, hemochromatosis $(n=6)$, primary biliary cirrhosis $(n=21)$, primary sclerosing cholangitis $(n=24)$, Wilson disease $(n=3)$, autoimmune hepatitis $(n=3)$, polycystic liver disease $(n=1)$, acute liver failure due to thrombosed hepatic artery $(n=3)$, Caroli disease $(n=1)$, drug-induced liver failure $(\mathrm{n}=1)$ and alpha-1-antitrypsin deficiency $(n=1)$. Again, individuals with ETOH tended to be male $(86.8 \%)$ compared with HCV $(76.7 \%)$ or other (67.3\%). All groups of patients used sleep aids to a similar extent. There was no difference in median MELD score at the time of transplant. All groups of patients stayed in hospital for a similar median number of postoperative days.

\section{Sleep satisfaction pre-LT and post-LT}

When examining the 57 patients with both pre-LT and post-LT questionnaires completed, $61 \%$ pre-LT patients reported satisfactory sleep experience in the past month versus $65 \%$ in the post-LT period (OR 1.17 [95\% CI 0.53 to 2.56]). Participants reported taking $\geq 30 \mathrm{~min}$ to fall asleep $36 \%$ of the time before and 25\% after LT, respectively (OR 0.60 [95\% CI 0.35 to 1.01]). Patients reported staying asleep for $\leq 6 \mathrm{~h} 45 \%$ of the time before and 34\% after LT, respectively (OR 0.65 [95\% CI 0.39 to 1.08]).

All questionnaires completed pre-LT and post-LT across types of liver disease were then evaluated, using at most one preoperative and one postoperative measure per person. The ETOH group improved dramatically from most sleep disturbance pre-LT (66.7\%) to least sleep disturbance post-LT (20.7\%, OR 0.13 [95\% CI 0.03 to 0.60]). HCV patients experienced no improvement in sleep disturbance, with $40 \%$ reporting sleep disturbance pre-LT and $38.4 \%$ post-LT (OR 0.90 [95\% CI 0.38 to 2.15]). Similarly, patients with other types of liver disease had no differences in reported sleep disturbance pre-LT at 33.1\% versus post-LT (27.2\%, OR 0.74 [95\% CI 0.35 to 1.57]).

Those with HCV had sleep latency of $47.8 \mathrm{~min}$ pre-LT and $37.1 \mathrm{~min}$ post-LT. Sleep duration was $6.9 \mathrm{~h}$ and $6.95 \mathrm{~h}$ pre-LT and post-LT, respectively. Patients with ETOH had the shortest sleep latency 
TABLE 2

Predictors of poor pretransplant sleep according to logistic regression analysis

\begin{tabular}{|c|c|c|c|}
\hline \multirow[b]{2}{*}{ Parameter } & \multicolumn{3}{|c|}{ Sleep* } \\
\hline & Latency & Duration & Satisfaction \\
\hline Age & $\begin{array}{c}0.97 \\
(0.92-1.02)\end{array}$ & $\begin{array}{c}1.01 \\
(0.97-1.06)\end{array}$ & $\begin{array}{c}0.98 \\
(0.93-1.02)\end{array}$ \\
\hline Female sex & $\begin{array}{c}3.53 \\
(1.16-11.51)^{\dagger}\end{array}$ & $\begin{array}{c}0.51 \\
(0.19-1.37)\end{array}$ & $\begin{array}{c}3.83 \\
(1.27-12.65)^{\dagger}\end{array}$ \\
\hline Sleep aid & $\begin{array}{c}2.07 \\
(0.29-18.32) \\
\end{array}$ & $\begin{array}{c}1.29 \\
(0.21-10.27) \\
\end{array}$ & $\begin{array}{c}2.13 \\
(0.30-15.54) \\
\end{array}$ \\
\hline $\begin{array}{l}\text { Primary Dx of ETOH } \\
\text { (relative to } \mathrm{HCV} \text { ) }\end{array}$ & $\begin{array}{c}0.19 \\
(0.009-1.47)\end{array}$ & $\begin{array}{c}0.72 \\
(0.14-3.78)\end{array}$ & $\begin{array}{c}5.82 \\
(1.04-40.58)^{\dagger}\end{array}$ \\
\hline $\begin{array}{l}\text { Primary Dx of other } \\
\text { liver diseases } \\
\text { (relative to HCV) }\end{array}$ & $\begin{array}{c}0.50 \\
(0.16-1.54)\end{array}$ & $\begin{array}{c}0.93 \\
(0.34-2.53)\end{array}$ & $\begin{array}{c}0.64 \\
(0.20-1.95)\end{array}$ \\
\hline Body mass index & $\begin{array}{c}0.95 \\
(0.84-1.07)\end{array}$ & $\begin{array}{c}0.97 \\
(0.88-1.07)\end{array}$ & $\begin{array}{c}0.99 \\
(0.87-1.11)\end{array}$ \\
\hline $\begin{array}{l}\text { Model for End-stage } \\
\text { Liver Disease score }\end{array}$ & $\begin{array}{c}0.97 \\
(0.90-1.04)\end{array}$ & $\begin{array}{c}0.99 \\
(0.93-1.05)\end{array}$ & $\begin{array}{c}0.91 \\
(0.83-0.97)^{\dagger}\end{array}$ \\
\hline
\end{tabular}

Data presented as OR $(95 \% \mathrm{Cl})$. ${ }^{*}$ Latency, duration and satisfaction as binary variables (note: an $O R<1$ suggests shorter sleep latency, longer sleep duration and more sleep satisfaction); ${ }^{\dagger}$ Associations with $P<0.05$. Dx Diagnosis; ETOH Alcoholic liver disease; HCV Hepatitis C virus

pre-LT $(21.1 \mathrm{~min})$ and $26.3 \mathrm{~min}$ post-LT, while mean sleep duration was $6.8 \mathrm{~h}$ pre-LT and $7.4 \mathrm{~h}$ post-LT.

Predictors of sleep parameters (Tables 2 and 3)

Logistic regression modelling was performed using, at most, one preoperative and one postoperative measure per person.

Pre-LT: Pre-LT patients with ETOH were significantly less likely to report satisfactory sleep than those with HCV (OR 5.8 [95\% CI 1.0 to 40.5]). Patients with HCV trended toward poor sleep satisfaction, as well as worse sleep latency and duration compared with both ETOH and other. Pre-LT patients with stage 3 encephalopathy took $119 \mathrm{~min}$ (95\% CI $29.3 \mathrm{~min}$ to $210.3 \mathrm{~min}$ ) longer than those with stage 1 encephalopathy to fall asleep.

Post-LT: Post-LT patients who underwent LT for ETOH slept much better than those transplanted for $\mathrm{HCV}$, with statistically significant less sleep disturbance (OR 0.50 [95\% CI 0.20 to 1.00]).

Both ETOH and other patients had significantly less sleep latency than $\mathrm{HCV}$ patients (OR 0.4 [95\% CI 0.2 to 0.9] and OR 0.5 [95\% CI 0.2 to 0.9 ], respectively) (22).

\section{DISCUSSION}

In the present retrospective study, we used a validated questionnaire (21-23) to evaluate sleep quality before and after LT. Sleep disturbance significantly affects quality of life, and is known to be prevalent in up to $48 \%$ of patients with advanced liver disease (7). This is postulated to be due to disrupted circadian rhythms in cirrhotic patients, caused by constantly elevated melatonin levels (24-26). Increased melatonin levels are hypothesized to alter function of the suprachiasmatic nucleus (27-29). Additional physiological processes that affect sleep in cirrhotic patients include endocrine abnormalities leading to melatonin derangement (29), decreased activation of the retinohypothalamic system (30), central nervous system effects of gut-derived toxins (31), and less sensory input due to decreased activity level and light exposure (29). These phenomena translate into abnormal sleep actigraphy with delayed bedtime, late wake-up time and evening chronotypology (8). There is also animal evidence of deranged sleep patterns in cirrhosis. Male rats with pharmacologically induced cirrhosis had progressively decreased total wake time, along with increased total slow wave and rapid eye movement sleep (32).
TABLE 3

Predictors of poor post-transplant sleep according to logistic regression analysis

\begin{tabular}{|c|c|c|c|}
\hline \multirow[b]{2}{*}{ Parameter } & \multicolumn{3}{|c|}{ Sleep* } \\
\hline & Latency & Duration & Satisfaction \\
\hline Age & $\begin{array}{c}0.99 \\
(0.97-1.03)\end{array}$ & $\begin{array}{c}0.97 \\
(0.94-0.99)^{\dagger}\end{array}$ & $\begin{array}{c}1.00 \\
(1.00-1.01)\end{array}$ \\
\hline Female sex & $\begin{array}{c}2.10 \\
(1.11-3.96)^{\dagger}\end{array}$ & $\begin{array}{c}1.54 \\
(0.83-2.93)\end{array}$ & $\begin{array}{c}1.40 \\
(0.80-2.70)\end{array}$ \\
\hline Sleeping aid & $\begin{array}{c}0.92 \\
(0.37-2.08)\end{array}$ & $\begin{array}{c}0.55 \\
(0.26-1.16)\end{array}$ & $\begin{array}{c}2.30 \\
(1.10-4.90)^{\dagger}\end{array}$ \\
\hline $\begin{array}{l}\text { Primary } \mathrm{Dx} \mathrm{ETOH} \text {, } \\
\text { relative to } \mathrm{HCV}\end{array}$ & $\begin{array}{c}0.40 \\
(0.16-0.95)^{\dagger}\end{array}$ & $\begin{array}{c}1.37 \\
(0.63-3.02)\end{array}$ & $\begin{array}{c}0.50 \\
(0.20-1.00)^{\dagger}\end{array}$ \\
\hline $\begin{array}{l}\text { Primary Dx of other } \\
\text { liver diseases, } \\
\text { relative to HCV }\end{array}$ & $\begin{array}{c}0.47 \\
(0.25-0.90)^{\dagger}\end{array}$ & $\begin{array}{c}1.10 \\
(0.59-2.01)\end{array}$ & $\begin{array}{c}0.60 \\
(0.30-1.10)\end{array}$ \\
\hline Body mass index & $\begin{array}{c}1.01 \\
(0.963-1.06)\end{array}$ & $\begin{array}{c}1.02 \\
(0.97-1.07)\end{array}$ & $\begin{array}{c}1.00 \\
(1.00-1.10)\end{array}$ \\
\hline $\begin{array}{l}\text { Model for End-stage } \\
\text { Liver Disease score }\end{array}$ & $\begin{array}{c}0.99 \\
(0.955-1.04)\end{array}$ & $\begin{array}{c}0.97 \\
(0.94-1.01)\end{array}$ & $\begin{array}{c}1.00 \\
(0.90-1.00)\end{array}$ \\
\hline Hospital discharge & $\begin{array}{c}0.99 \\
(0.97-1.00)\end{array}$ & $\begin{array}{c}1.00 \\
(0.99-1.02)\end{array}$ & $\begin{array}{c}1.00 \\
(0.98-1.00)\end{array}$ \\
\hline
\end{tabular}

Data presented as OR $(95 \% \mathrm{Cl})$ for the association between each of three sleep outcomes - latency, duration and satisfaction - and diagnostic group before and at least 180 days after liver transplantation. Questionnaires were administered at least six months after transplant. When $>1$ was available, the questionnaire furthest away from liver transplantation was selected. An $O R<1$ suggests shorter sleep latency, longer sleep duration and more sleep satisfaction. ${ }^{*}$ Latency, duration and satisfactory as binary; ${ }^{\dagger}$ Associations with $P<0.05$. Dx Diagnosis; ETOH Alcoholic liver disease; HCV Hepatitis C virus

In our study, we found that overall sleep parameters did not improve following LT, which was likely driven by the HCV group (the largest) based on subsequent analysis. Specifically, when reviewing all questionnaires, patients with ETOH experienced dramatically less sleep disturbance following LT compared with pre-LT (OR 0.13 [95\% CI 0.03 to 0.60]). In contrast, $\mathrm{HCV}$ patients remained without improvement following LT (OR 0.90 [95\% CI 0.38 to 2.15]). On logistic regression, patients transplanted for ETOH had statistically less sleep satisfaction pre-LT (OR 5.8 [95\% CI 1.0 to 40.5]) and significantly better sleep satisfaction post-LT (OR 0.50 [95\% CI 0.20 to 1.00]) compared with those transplanted for HCV. The HCV group had worse sleep latency, duration and satisfaction after LT compared with the ETOH group. This was consistent with our a priori hypothesis that universal HCV recurrence in long-term LT survivors would result in decreased sleep quality as shown in other areas of HRQoL (33-37). This may be due to liver dysfunction caused by the virus, or may be a direct viral cerebral effect $(38,39)$ and can be considered to be an extrahepatic manifestation of HCV. In contrast, the improvement and overall better sleep parameters in $\mathrm{ETOH}$ patients may be attributed to the resolution of disease in most patients as opposed to the universal recurrence of $\mathrm{HCV}$ after LT.

Stage 3 encephalopathy was also a predictor of decreased sleep quality before LT in our study. Patients with stage 3 encephalopathy took 119 min longer to fall asleep than patients with stage 1 encephalopathy, which was likely a reflection of worse circadian physiology. LT then corrected circadian rhythms, with patients with stage 3 encephalopathy before LT having a quality of sleep similar to that of patients with stage 1 encephalopathy. Not surprisingly, use of a sleep aid postLT was independently associated with better sleep satisfaction.

Various quality of life questionnaires incorporate sleep as a parameter. The Liver Disease Quality of Life instrument has been developed and validated in patients with advanced, chronic liver disease (40). It incorporates not only aspects related to sleep, but also multiple other items such as liver disease-related symptoms, their effects on activities 
of daily living, concentration, memory and sexual functioning. The sleep-related questions pertained principally to the quality of sleep and fatigue as a consequence. A better HRQoL has been shown to predict better survival in patients with cirrhosis (7). A survey of pediatric LT recipients found that poor sleep quality after LT had a significant impact on HRQoL (41). In a smaller cross-sectional study of pre-LT and post-LT patients, $73 \%$ of pre-LT and $77 \%$ of post-LT patients complained of poor sleep quality (42). The different findings in our study may be due to our use of a standardized sleep questionnaire, with different definitions as to what constitutes impaired sleep latency and duration.

The BNSQ is comprised of 21 different questions, with 27 total items covering sleep complaints. These include difficulty in initiating and maintaining sleep, general sleep habits, subjective sleep quality, use of sleep-inducing medication, excessive daytime sleepiness, napping and snoring. The questionnaire takes $5 \mathrm{~min}$ to $10 \mathrm{~min}$ to complete and is self-reported. Participants assign scores for most of these items, ranging from 1 (mild or infrequently present) to 5 (severe or frequently present). Other questions relating to sleep duration and sleep latency require specific durations or times to be assigned. The BNSQ has been administered to various patient populations, including those with chronic conditions (23), and has been confirmed to be reproducible and reliable. The three items from this questionnaire (overall sleep satisfaction, sleep latency, and sleep duration) that we chose to evaluate have been shown to most closely correlate with objective sleep polysomnography $(21,22)$.

Our observational study had certain limitations. The questionnaires were not administered systematically, and questionnaire responses were analyzed in a retrospective manner.

Additionally, there may have been a selection bias in terms of the type of patient who agreed to complete a questionnaire before LT; however, it is likely nondifferential across types of liver disease. Use of self-reported questionnaires for sleep quality assessment may lead to recall bias that can misclassify patients. Physical symptoms may dominate a patient's quality of life before LT, with sleep disturbance being less important. However, because LT recipients improve physically, patients may report sleep disturbance more when physical issues are less consuming, possibly underestimating the benefit of orthotopic LT on sleep quality. Sleep quality is notoriously difficult to measure, and

\section{REFERENCES}

1. OPTN/SRTR 2013 Annual Data Report: Liver. Am J Transpl 2015;15(Suppl 2):1-28.

2. Santos RJ, Miyazaki MC, Domingos NA, Valerio NI, Silva RF, Silva RC. Patients undergoing liver transplantation: Psychosocial characteristics, depressive symptoms, and quality of life.

Transplant Proc 2008;40:802-4.

3. van Ginneken BT, van den Berg-Emons RJ, Kazemier G, Metselaar HJ, Tilanus HW, Stam HJ. Physical fitness, fatigue, and quality of life after liver transplantation. Eur J Appl Physiol 2007;100:345-53.

4. Russell RT, Feurer ID, Wisawatapnimit P, Salomon RM, Pinson CW. The effects of physical quality of life, time, and gender on change in symptoms of anxiety and depression after liver transplantation. J Gastrointest Surg 2008;12:138-44.

5. Roth T, Ancoli-Israel S. Daytime consequences and correlates of insomnia in the United States: Results of the 1991 National Sleep Foundation Survey. II. Sleep 1999;(22 Suppl 2):S354-8.

6. Krasnoff JB, Vintro AQ, Ascher NL, Bass NM, Dodd MJ, Painter PL. Objective measures of health-related quality of life over 24 months post-liver transplantation. Clin Transplant 2005;19:1-9.

7. Kanwal F, Gralnek IM, Hays RD, et al. Health-related quality of life predicts mortality in patients with advanced chronic liver disease. Clin Gastroenterol Hepatol 2009; 7:793-9.

8. Cordoba J, Cabrera J, Lataif L, Penev P, Zee P, Blei AT. High prevalence of sleep disturbance in cirrhosis. Hepatology 1998;27:339-45.

9. Martino ME, Romero-Vives M, Fernandez-Lorente J, De Vicente E, Barcena R, Gaztelu JM. Sleep electroencephalogram alterations disclose initial stage of encephalopathy. Methods Find Exp Clin Pharmacol 2002;(24 Suppl D):119-22.

10. Cordoba J, Steindl P, Blei AT. Melatonin arrhythmia is corrected after liver transplantation. Am J Gastroenterol 2009;104:1862-3. future work should likely combine multiple modalities of sleep assessment. These may include wrist actigraphy $(8,43)$ (measures arm movement to infer sleep and wakefulness) and/or polysomnography (which measures cerebral and muscle activity, and eye movement). The present study did not have the statistical power to examine more subgroups of patients and could not explore other liver diseases. Finally, no control group was examined. However, a large population-based Canadian study examining mental health, including sleep disturbance, using a self-reported questionnaire found a prevalence of $15.6 \%$ to $15.9 \%$ for individuals 45 to 74 years of age and $12.6 \%$ for the those 35 to 44 years of age (44). Our prevalence post-LT of inadequate sleep quality was considerably higher and highlights the need for further work in this field.

\section{CONCLUSION}

Patients who undergo LT for HCV continue to experience higher rates of sleep disturbance after LT, possibly due to the universal recurrence of $\mathrm{HCV}$. The advent of highly effective HCV therapies may provide an opportunity to both prevent development of recurrent liver disease with disturbed circadian pattern and prevent the damaging effects of HCV directly on the brain's circadian rhythms, thereby improving sleep quality in this patient subpopulation. Patients transplanted for ETOH, a disease that recurs much less often, have significantly improved sleep parameters after LT. Physicians should remain alert to this domain of HRQoL in longterm LT survivors, and diligently question patients about sleep quality. Sleep disturbance after LT should be addressed and managed, so as to ultimately improve HRQoL for these patients.

ACKNOWLEDGEMENT: The authors thank Myriam Fernandez for her management of the transplant database.

DISCLOSURES: The authors have no financial disclosures or conflicts of interest to declare.

FUNDING: CIHR fellowship to M Bhat.

11. Lowe D, O'Grady JG, McEwen J, Williams R. Quality of life following liver transplantation: A preliminary report. J R Coll Physicians Lond 1990;24:43-6.

12. Bonsel GJ, Essink-Bot ML, Klompmaker IJ, Slooff MJ. Assessment of the quality of life before and following liver transplantation. First results Transplantation 1992;53:796-800.

13. Tarter RE, Van Thiel DH, Hegedus AM, Schade RR, Gavaler JS, Starzl TE. Neuropsychiatric status after liver transplantation. J Lab Clin Med 1984;103:776-82.

14. Partinen M, Gislason T. Basic Nordic Sleep Questionnaire (BNSQ): A quantitated measure of subjective sleep complaints. J Sleep Res Jun 1995;4(S1):150-5.

15. Lindblom N, Kivinen S, Heiskala H, Laakso ML, Kaski M. Sleep disturbances in aspartylglucosaminuria (AGU): A questionnaire study. J Inherit Metab Dis 2006;29:637-46.

16. Eriksen W, Bjorvatn B, Bruusgaard D, Knardahl S. Work factors as predictors of poor sleep in nurses' aides. Int Arch Occup Environ Health 2008;81:301-10.

17. Strang-Karlsson S, Raikkonen K, Kajantie E, et al. Sleep quality in young adults with very low birth weight - the Helsinki study of very low birth weight adults. J Pediatr Psychol 2008;33:387-95.

18. Devine EB, Hakim Z, Green J. A systematic review of patientreported outcome instruments measuring sleep dysfunction in adults. Pharmacoeconomics 2005;23:889-912.

19. Vaari T, Engblom J, Helenius H, Erkkola R, Polo-Kantola P. Survey of sleep problems in 3421 women aged $41-55$ years. Menopause Int 2008;14:78-82.

20. Sarti CD, Chiantera A, Graziottin A, et al. Hormone therapy and sleep quality in women around menopause. Menopause 2005;12:545-51. 
21. Kawada T, Suzuki S, Aoki S, Ogawa M. Relationship between subjective sleep rating and objective sleep parameters: A case study. Environ Res 1993;60:136-44.

22. Armitage R, Trivedi M, Hoffmann R, Rush AJ. Relationship between objective and subjective sleep measures in depressed patients and healthy controls. Depress Anxiety 1997;5:97-102.

23. Janson C, De Backer W, Gislason T, et al. Increased prevalence of sleep disturbances and daytime sleepiness in subjects with bronchial asthma: A population study of young adults in three European countries. Eur Respir J 1996;9:2132-8.

24. Steindl PE, Finn B, Bendok B, Rothke S, Zee PC, Blei AT. Disruption of the diurnal rhythm of plasma melatonin in cirrhosis. Ann Intern Med 1995;123:274-7.

25. Montagnese S, Middleton B, Mani AR, Skene DJ, Morgan MY. Sleep and circadian abnormalities in patients with cirrhosis: Features of delayed sleep phase syndrome? Metab Brain Dis 2009;24:427-39.

26. Cordoba J, Dupuis J, Gottstein J, Blei AT. Stenosis of a portacaval anastomosis affects circadian locomotor activity in the rat: A multivariable analysis. Am J Physiol 1997;273(6 Pt 1):G1218-25.

27. Steindl PE, Gottstein J, Blei AT. Disruption of circadian locomotor activity in rats after portacaval anastomosis is not gender dependent. Hepatology 1995;22:1763-8.

28. Zee PC, Mehta R, Turek FW, Blei AT. Portacaval anastomosis disrupts circadian locomotor activity and pineal melatonin rhythms in rats. Brain Res 1991;560:17-22.

29. Montagnese S, Middleton B, Mani AR, Skene DJ, Morgan MY. On the origin and the consequences of circadian abnormalities in patients with cirrhosis. Am J Gastroenterol 2010;105:1773-81.

30. Reichenbach A, Fuchs U, Kasper M, el-Hifnawi E, Eckstein AK. Hepatic retinopathy: Morphological features of retinal glial (Muller) cells accompanying hepatic failure. Acta Neuropathol 1995;90:273-81.

31. Steindl PE, Coy DL, Finn B, Zee PC, Blei AT. A low-protein diet ameliorates disrupted diurnal locomotor activity in rats after portacaval anastomosis. Am J Physiol 1996;271(4 Pt 1):G555-560.

32. Jimenez-Anguiano A, Diaz-Medina V, Farfan-Labonne BE, et al. Modification of sleep architecture in an animal model of experimental cirrhosis. World J Gastroenterol 2009;15:5176-80.
33. Feurer ID, Wright JK, Payne JL, et al. Effects of hepatitis C virus infection and its recurrence after liver transplantation on functional performance and health-related quality of life. J Gastrointest Surg 2002;6:108-15.

34. Paterson DL, Gayowski T, Wannstedt CF, et al. Quality of life in long-term survivors after liver transplantation: Impact of recurrent viral hepatitis C virus hepatitis. Clin Transplant 2000;14:48-54.

35. Gayowski T, Wagener MM, Marino IR, Singh N. Quality of life and functional status of liver transplant recipients with recurrent viral hepatitis C. Transplant Proc 1999;31:1386-7.

36. Bona MD, Rupolo G, Ponton P, et al. The effect of recurrence of $\mathrm{HCV}$ infection of life after liver transplantation. Transpl Int 1998;(11 Suppl 1):S475-479.

37. De Bona M, Ponton P, Ermani M, et al. The impact of liver disease and medical complications on quality of life and psychological distress before and after liver transplantation. J Hepatol 2000;33:609-15.

38. Forton DM, Allsop JM, Main J, Foster GR, Thomas HC, Taylor-Robinson SD. Evidence for a cerebral effect of the hepatitis C virus. Lancet 2001;358:38-9.

39. Forton DM, Thomas HC, Murphy CA, et al. Hepatitis C and cognitive impairment in a cohort of patients with mild liver disease. Hepatology 2002;35:433-9.

40. Gralnek IM, Hays RD, Kilbourne A, et al. Development and evaluation of the Liver Disease Quality of Life instrument in persons with advanced, chronic liver disease - the LDQOL 1.0. Am J Gastroenterol 2000;95:3552-65.

41. Fredericks EM, Dore-Stites D, Calderon SY, et al. Relationship between sleep problems and health-related quality of life among pediatric liver transplant recipients. Liver Transpl 2012;18:707-15.

42. Rodrigue JR, Nelson DR, Reed AI, Hanto DW, Curry M. Fatigue and sleep quality before and after liver transplantation. Prog Transplant 2010;20:221-33.

43. NIH State-of-the-Science Conference Statement on manifestations and management of chronic insomnia in adults. NIH Consens State Sci Statements. June 13 to 15,$2005 ; 22: 1-30$.

44. Tjepkema M. Insomnia. Health Rep 2005;17:9-25. 


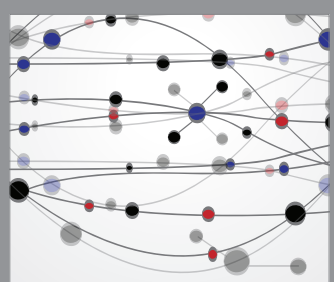

The Scientific World Journal
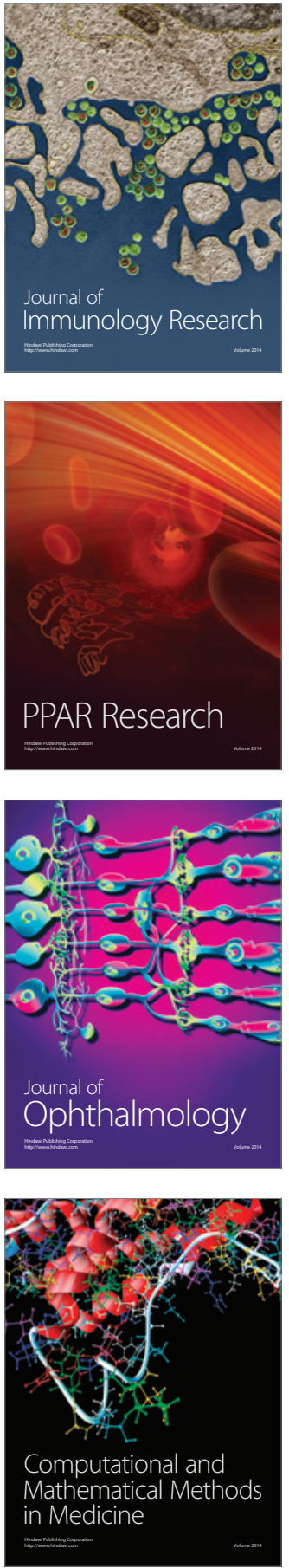

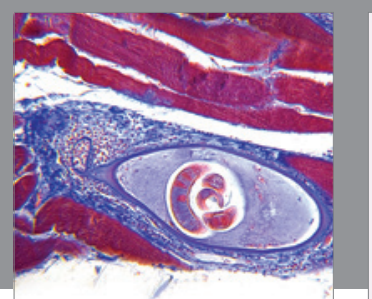

Gastroenterology Research and Practice

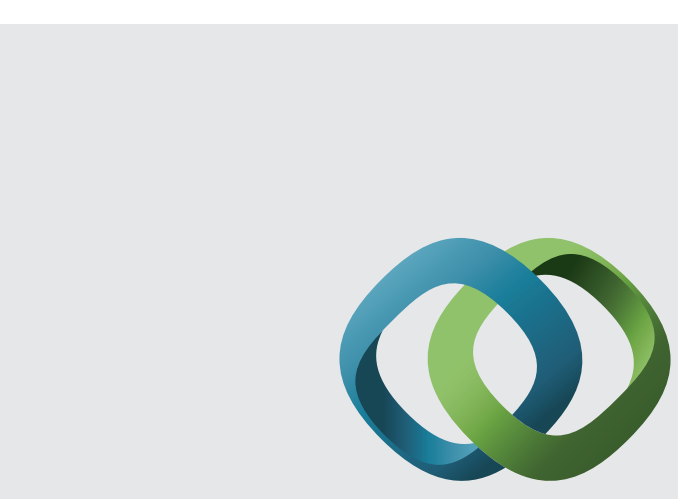

\section{Hindawi}

Submit your manuscripts at

http://www.hindawi.com
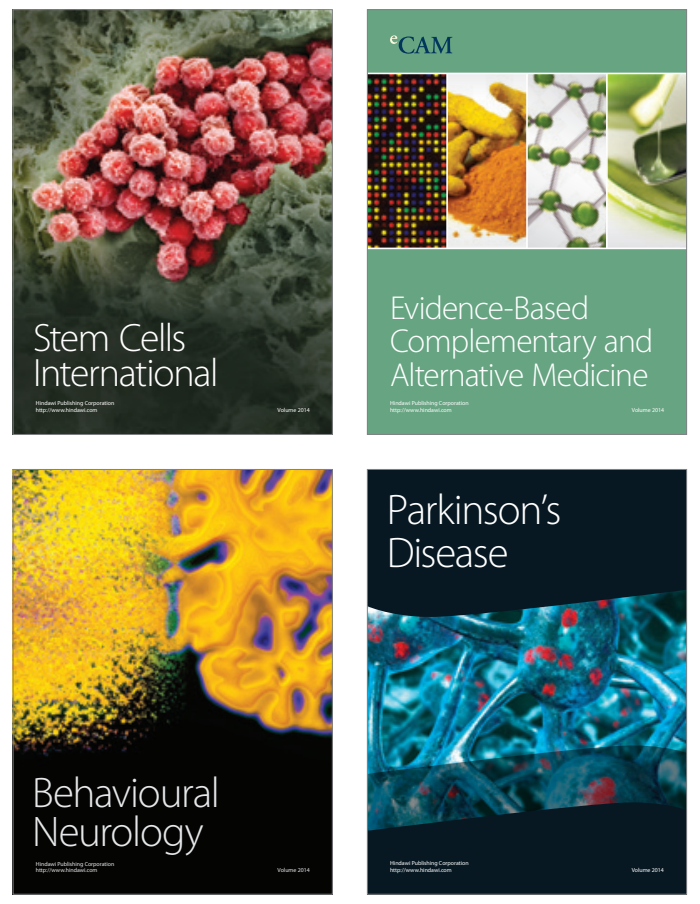
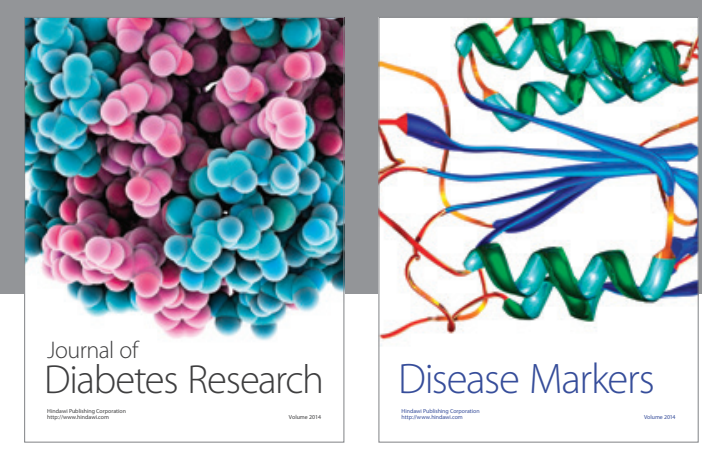

Disease Markers
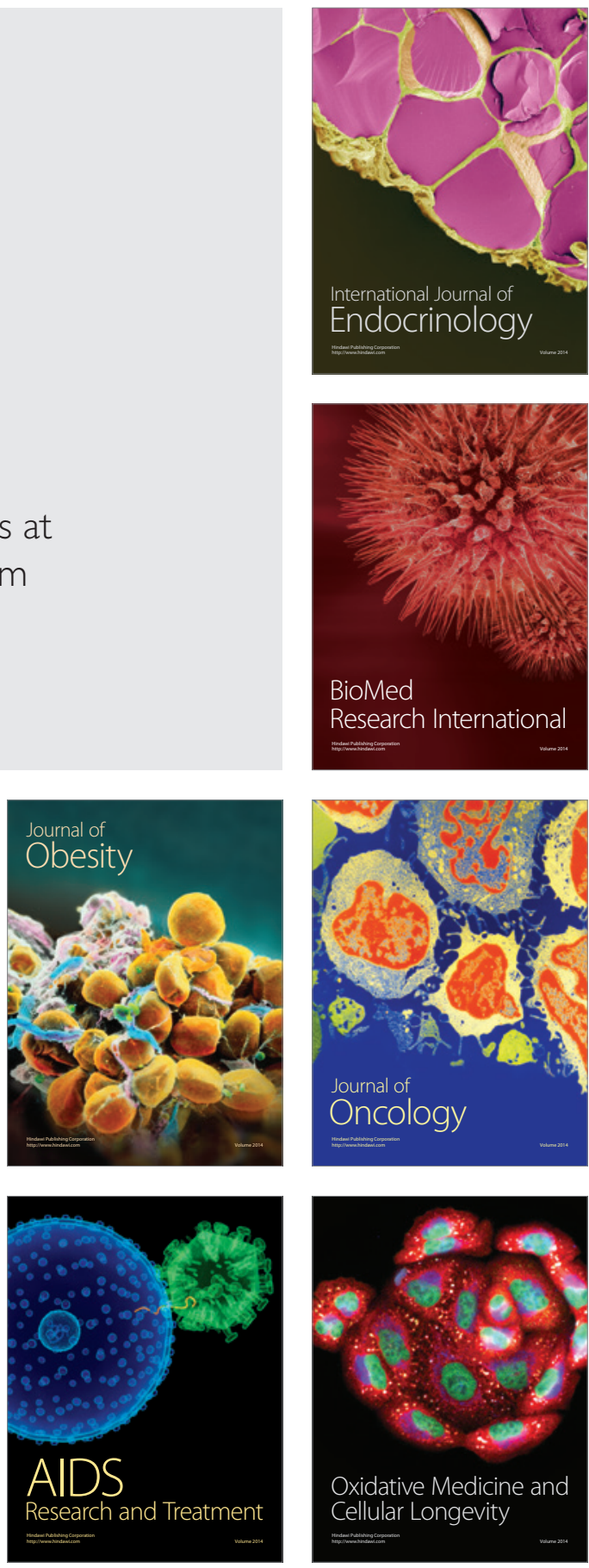